\title{
miR-425-5p is associated with poor prognosis in patients with breast cancer and promotes cancer cell progression by targeting PTEN
}

\author{
SHENG XIAO $^{1 *}$, HONGJIA ZHU ${ }^{1 *}$, JIAN LUO $^{1}$, \\ ZHENRU WU ${ }^{2}$ and MINGJUN XIE ${ }^{1,3}$ \\ ${ }^{1}$ School of Clinical Medicine, Southwest Medical University, Luzhou, Sichuan 646000; \\ ${ }^{2}$ Laboratory of Pathology, West China Hospital, Chengdu, Sichuan 610041; \\ ${ }^{3}$ Department of Breast Surgery, The First People's Hospital of Yibin, \\ Yibin, Sichuan 644000, P.R. China
}

Received May 31, 2019; Accepted September 13, 2019

DOI: 10.3892/or.2019.7371

\begin{abstract}
Breast cancer (BC) is the most common invasive cancer in women, and it imposes a heavy burden on patients. microRNAs (miRNAs/miRs) have been found to play an important role in the development of tumors, but their role in the malignant progression of $\mathrm{BC}$ is unclear. In the present study, the expression level of miR-425-5p was examined in patients with $\mathrm{BC}$, and its association with prognosis was investigated. In vitro experiments were performed to examine role of miR-425-5p in the development of BC cells. A downstream target gene of miR-425-5p was predicted using a miRNA target prediction tool and validated with a luciferase reporter assay. It was found that miR-425-5p expression was increased in BC tissues and cell lines, and was associated with tumor size, clinical stage, lymph node metastasis, distant metastasis and poor overall survival in patients with BC. Knockdown of miR-425-5p in $\mathrm{BC}$ cell lines inhibited proliferation and migration. PTEN was identified as a downstream target gene of miR-425-5p. Overexpression of PTEN was demonstrated to partially inhibit the promotional effect of miR-425-5p on cell proliferation and migration. Taken together, miR-425-5p is associated with poor prognosis, and promotes cell proliferation and migration via PTEN. Thus, miR-425-5p may serve as a therapeutic and prognostic marker for BC.
\end{abstract}

Correspondence to: Professor Mingjun Xie, School of Clinical Medicine, Southwest Medical University, 1 Xianglin Road, Luzhou, Sichuan 646000, P.R. China

E-mail: xiemingjun886@126.com

*Contributed equally

Key words: breast cancer, miR-425-5p, prognosis, phosphatase and tensin homolog, cell proliferation, cell invasion

\section{Introduction}

Breast cancer (BC) is the most common cancer in women, and was the second leading cause of cancer-related mortality worldwide in 2015 , second only to lung cancer $(1,2)$. China has many patients with $\mathrm{BC}$, and a large number of these patients suffer from personal and family problems caused by the disease (3). BC patients often have metastasis and recurrence despite the surgical removal of primary tumors (4). Previous studies have found that specific molecular targeted therapy can improve the quality of life of patients and bring new hope $(5,6)$. Although many reliable molecular targets for the treatment of $\mathrm{BC}$ have been discovered, current molecular targeted therapies for BC are expensive, are not effective for all patients and most patients develop resistance (7).

microRNAs (miRNAs/miRs) are a class of single-stranded non-coding small RNAs 21-23 nt in length (8). Mature miRNAs are integrated into the RNA-induced silencing complex and bind to specific sites in the non-coding 3'untranslated region (3'UTR) of target mRNA in an incomplete complementary manner, to mediate the degradation of RNA or inhibit the translation of proteins, thus playing a key role in the silencing of RNA and the regulation of post-transcriptional expression $(9,10)$. A large number of studies have found that miRNAs are abnormally expressed in a variety of malignant tumors and are associated with malignant tumor growth (11-14). Expression of miR-425-5p is upregulated in renal cell carcinoma and promotes cell viability, invasion and migration (15). In prostate cancer, high miR-425-5p expression can significantly promote the proliferation, migration and invasion of tumor cells (16). However, the role of miR-425-5p in $\mathrm{BC}$ remains unknown, and the underlying functional mechanism of the effects of miR-425-5p in BC progression remains to be further studied.

In the present study, the expression of miR-425-5p in BC was determined by RT-qPCR, and the association of miR-425-5p expression with the clinicopathological parameters and prognosis of patients with $\mathrm{BC}$ was analyzed. A 
downstream target of miR-425-5p was also investigated. The current study may provide a scientific basis for exploring the role of miR-425-5p in $\mathrm{BC}$, thus providing new molecular targets for $\mathrm{BC}$ treatment.

\section{Materials and methods}

Clinical specimens. A total of 77 samples of BC tumor tissue and paired adjacent tissue were collected from patients with BC at the First People's Hospital of Yibin (Yibin, China). Tissue specimens were collected from patients (age range, 30-82 years; all patients were female) with primary BC who underwent surgical resection between September 2010 and December 2012. All patients were histologically diagnosed with invasive ductal breast cancer after surgery. Patient information on age,tumor size, clinical stage, lymph node metastasis, distant metastasis, and information on the expression of estrogen receptor, progesterone receptor and human epidermal growth factor receptor 2 was collected $(17,18)$. This study was conducted in accordance with the Helsinki Declaration and was approved by the Ethics Review Committee of the Yibin First People's Hospital and the Ethics Review Committee of Southwest Medical University (Luzhou, China). Written informed consent was obtained from all patients for the use of their tissue in this study.

Cell culture and transfection. Five BC cell lines (MCF-7, SKBR-3, MDA-MB-231, MDA-MB-468 and BT-20) and a normal human mammary epithelial cell line (MCF-10A) were obtained from the Institute of Biochemistry and Cell Biology (Chinese Academy of Sciences). All cell lines were cultured in DMEM containing $10 \%$ fetal bovine serum (FBS) and incubated at $37^{\circ} \mathrm{C}$ in $5 \% \mathrm{CO}_{2}$.

MCF-7 and MDA-MB-231 cells $\left(3 \times 10^{5}\right)$ were transfected with pre-miR-425-5p (miR-425-5p), mimic negative control (NC), miR-425-5p inhibitor, inhibitor NC or pcDNA-PTEN (Shanghai GenePharma Co., Ltd.). pcDNA plasmid without PTEN was used as a negative control. The sequences of the miRNA mimic, inhibitor and controls are presented in Table SI. The concentrations used for mimic, inhibitor and pcDNA were 50, $100 \mathrm{nM}$ and $1000 \mathrm{ng} / \mathrm{ul}$, respectively) Cells were transfected using Lipofectamine 3000 reagent (Invitrogen; Thermo Fisher Scientific, Inc.) according to the manufacturer's instructions. Subsequent experiments were performed $24-72 \mathrm{~h}$ after transfection.

Reverse transcription quantitative PCR (RT-qPCR). Total RNA was extracted from BC tissues, paired adjacent tissue and cell lines using TRIzol reagent (Takara Bio, Inc.). PrimeScript RT Reagent Kit (Takara Bio, Inc.) was used for the reverse transcription of cDNA. The temperature protocol for RT was as follows: $35^{\circ} \mathrm{C}$ for $5 \mathrm{~min}$, followed by $42^{\circ} \mathrm{C}$ for $40 \mathrm{~min}$ and $75^{\circ} \mathrm{C}$ for $5 \mathrm{~min}$. Next, qPCR was performed with SYBR Premix Ex Taq II (Takara Bio, Inc.) and a LightCycler system (Roche Diagnostics $\mathrm{GmbH}$ ). The results were analyzed using the $2^{-\Delta \Delta \mathrm{Cq}}$ method (19). U6 was used as an internal control for microRNA, and GAPDH was used for mRNA. The sequences of the primers used for each gene are presented in Table SII. The thermocycling conditions for qPCR were as follows: Initial activation step at $95^{\circ} \mathrm{C}$ for $15 \mathrm{~min}$ followed by 40 cycles of denaturation at $94^{\circ} \mathrm{C}$ for $15 \mathrm{sec}$, annealing at $55^{\circ} \mathrm{C}$ for $30 \mathrm{sec}$ and extension at $72^{\circ} \mathrm{C}$ for $30 \mathrm{sec}$.

Western blot analysis. Total protein from BC cell lines, a normal human mammary epithelial cell line $\left(1 \times 10^{6}\right)$ and tissues was extracted using RIPA lysis buffer (Beyotime Institute of Biotechnology Co., Ltd.). Protein was quantified using the Bradford protein assay (Bio-Rad Laboratories, Inc.) with a Nanodrop spectrophotometer, and an equal amount (30 $\mu \mathrm{g})$ was added to each well of $12 \%$ gels and resolved by SDS-PAGE. Next, proteins were transferred to PVDF membranes and were blocked by incubation for $1 \mathrm{~h}$ at room temperature with $5 \%$ non-fat powdered milk. The membranes were probed at $4^{\circ} \mathrm{C}$ overnight with antibodies against PTEN (1:5,000; ab32199; Abcam) and anti-GAPDH (1:5,000; ab181602; Abcam). Subsequently, the PVDF membranes were incubated with horseradish peroxidase-conjugated secondary antibody (1:5,000; ab6721; Abcam) at room temperature for $1 \mathrm{~h}$. Protein detection was performed using incubation with an enhanced chemiluminescence solution (EMD Millipore), and imaged using a ChemiDoc Imaging System (Bio-Rad Laboratories, Inc.). GAPDH was used as the internal loading control in the western blot. The protein bands were quantified using QuantityOne software v4.6.7 (Bio-Rad Laboratories, Inc.), and the values are expressed relative to GAPDH. Each experiment was repeated three times.

Cell-Counting Kit-8 assay (CCK-8). Following transfection, cells were seeded onto 96 -well plates and incubated at $37^{\circ} \mathrm{C}$ for 24,48 or $72 \mathrm{~h}$ before the addition of CCK-8 reagent. Next, $10 \mu \mathrm{lCCK}-8$ reagent was added to each well, and after $2 \mathrm{~h}$ of incubation at $37^{\circ} \mathrm{C}$, absorption was determined at $450 \mathrm{~nm}$ was determined by microplate spectrophotometer.

Colony-forming assay. Transfected cells were seeded into 6 -well plates and cultured for 14 days. At that time, the colonies that had formed were fixed with $4 \%$ paraformaldehyde for $30 \mathrm{~min}$ at room temperature and stained with $0.1 \%$ crystal violet for $15 \mathrm{~min}$ at room temperature. Finally, the cell colonies were counted with a light microscope (Olympus Corporation; magnification, $\mathrm{x} 40$ ).

Transwell migration and invasion assays. For the invasion assay, Tranwell inserts were precoated with Matrigel $(1 \mathrm{mg} / \mathrm{ml})$ at $37^{\circ} \mathrm{C}$ for $30 \mathrm{~min}$. Transwells were uncoated for the migration assay. Transfected cells were seeded into the upper chamber with serum-free media. In the bottom chamber, $500 \mu \mathrm{l}$ DMEM containing 10\% FBS functioning as a chemoattractant was added. After $48 \mathrm{~h}$ of incubation, the migrated or invaded cells were fixed with $4 \%$ paraformaldehyde for $30 \mathrm{~min}$ at room temperature and stained with $0.1 \%$ crystal violet for $15 \mathrm{~min}$ at room temperature. Finally, the migrated or invaded cells were counted with a Leica DM IL LED inverted light microscope (Leica Microsystems, Inc.; magnification, x100). Five microscopic fields of each well were randomly selected and the number of cells in microscopic fields was counted.

5-Ethynyl-2'-deoxyuridine (EdU) assay. Following transfection, cells were seeded into 96 -well plates and incubated at $37^{\circ} \mathrm{C}$ until the cells reached $30 \%$ confluence. An EdU assay was performed using a Cell-Light EdU Apollo 567 in vitro kit 
A
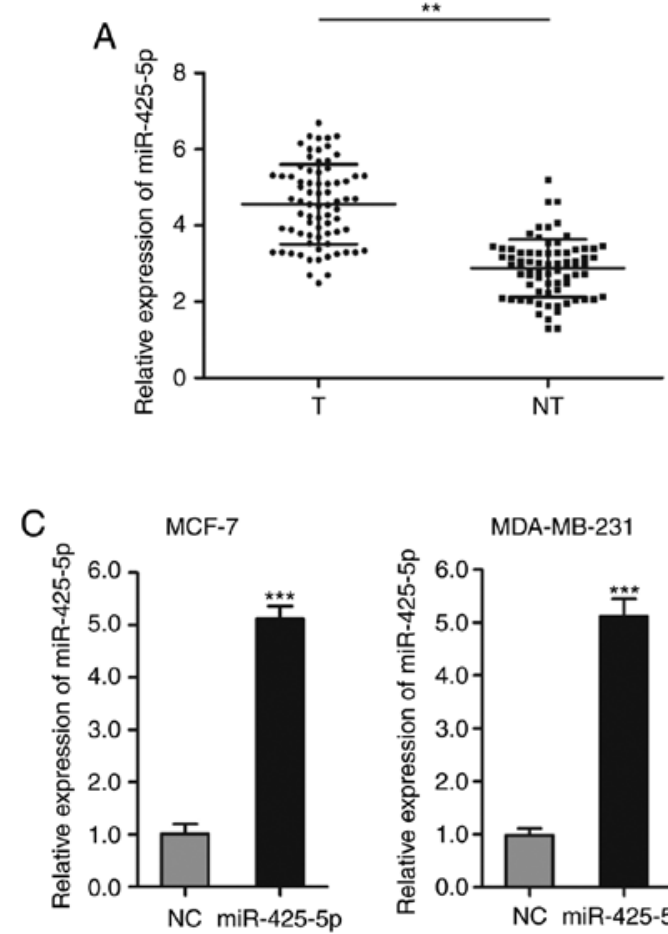

B

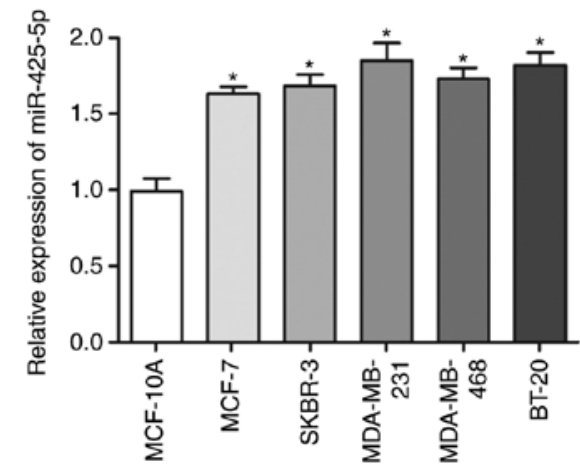

D

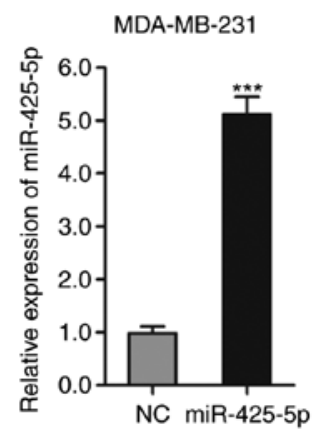

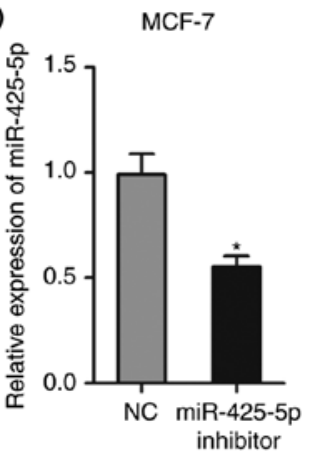

MDA-MB-231

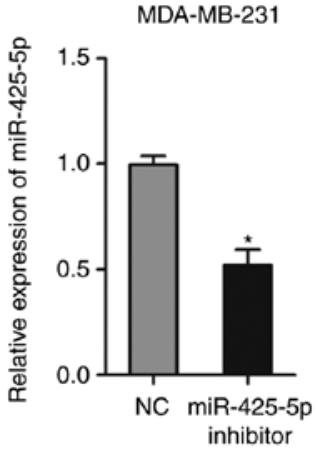

Figure 1. Expression of miR-425-5p in BC tissues and cell lines. (A) Relative expression of miR-425-5p in BC tumor tissue and paired adjacent tissue. (B) Relative expression of miR-425-5p in BC cell lines. (C) Expression of miR-425-5p in MCF-7 and MDA-MB-231 cells transfected with pre-miR-425-5p. (D) Expression of miR-425-5p in MCF-7 and MDA-MB-231 cells transfected with miR-425-5p inhibitor. ${ }^{*} \mathrm{P}<0.05,{ }^{* *} \mathrm{P}<0.01$ and ${ }^{* * *} \mathrm{P}<0.001$. miR, microRNA; $\mathrm{BC}$, breast cancer; NC, negative control; T, tumor tissue; NT, paired adjacent tissue.

(cat. no. 100T; Ruibo Biotechnology Co., Ltd.). According to manufacturer's instructions, the cells were incubated with EdU $(50 \mu \mathrm{M})$ for $120 \mathrm{~min}, 0.5 \%$ Triton $\mathrm{X}$ and ApolloR reaction cocktail $(100 \mu \mathrm{l})$ for $30 \mathrm{~min}$, and Hoechst 33342 (100 $\mu \mathrm{l})$ for 30 min sequentially. Cell proliferation was analyzed using the mean number of the cells in three fields for each sample using a fluorescence microscope (Lionheart; BioTek Instruments, Inc.; magnification, x100).

Luciferase reporter assay. The online miRNA databases Oncomir (http://www.oncomir.org/), MiRanda (http://www. microrna.org/microrna/home.do), miRWalk (http://mirwalk. umm.uni-heidelberg.de/) and TargetScan (http://www. targetscan.org) were used to identify downstream target genes of miR-425-5p. The wild-type (WT) PTEN 3' 3'UTR and mutant (MUT) PTEN 3'UTR oligonucleotides containing the putative binding site of miR-425-5p were cloned into the firefly luciferase-expressing pMIR-REPORT vector (Obio Technology Corp., Ltd.). These constructs were co-transfected with inhibitor NC or miR-425-5p inhibitor into MCF-7 and MDA-MB-231 cells. After $48 \mathrm{~h}$ of transfection, luciferase activity was determined using the Dual-Luciferase Reporter Assay kit (Promega Corporation) according to the manufacturer's protocol. The ratio of Renilla luciferase activity to firefly luciferase activity was calculated.

Statistical analysis. The statistical data were analyzed using SPSS version 22.0 software (IBM Corp.) and GraphPad Prism version 6.0 software (GraphPad Software Inc.). The differences between groups were analyzed using paired or unpaired $\mathrm{t}$ test and one-way analysis of variance, followed by the Newman-Keuls test. Kaplan-Meier and log-rank tests were used to assess recurrence-free survival (RFS) and disease-specific survival (DSS) times. For Kaplan-Meier curves, patients were divided into high and low expression groups using the mean expression (0.2) as the cut-off value. Correlation analysis was performed using Spearman's rank correlation test. The $\chi^{2}$ test was used to analyze the association of miR-425-5p expression with the clinicopathological characteristics of BC. Univariate and multivariate Cox regression analyses were performed to analysis the prognostic significance of miR-425-5p. $\mathrm{P}<0.05$ were considered to indicate a statistically significant difference.

\section{Results}

miR-425-5p is upregulated in BC tissues and cell lines. RT-qPCR was performed to detect the expression of miR-425-5p in BC tumor tissue, paired adjacent tissue and cell lines. The results showed that miR-425-5p was higher in BC tissues compared with in paired adjacent tissue (Fig. 1A). The expression of miR-425-5p was also higher in BC cell lines compared with human mammary epithelial cells (Fig. 1B). To further explore the role of miR-425-5p in BC, MCF-7 and MDA-MB-231 cells were transfected with pre-miR-425-5p to increase the expression of miR-425-5p (Fig. 1C), and miR-425-5p inhibitor to knockdown the expression of miR-425-5p (Fig. 1D).

High expression of miR-425-5p is associated with aggressive clinicopathological features and poor prognosis in 
Table I. Association between miR-425-5p and clinicopathological features of patients with breast cancer.

miR-425-5p expression, $\mathrm{n}$

\begin{tabular}{|c|c|c|c|c|}
\hline Variables & Cases, $\mathrm{n}$ & Low $(n=28)$ & High $(n=49)$ & P-value \\
\hline Age, years & & & & 0.659 \\
\hline$<45$ & 30 & 10 & 20 & \\
\hline$\geq 45$ & 47 & 18 & 29 & \\
\hline Tumor size, $\mathrm{cm}$ & & & & 0.003 \\
\hline$\leq 2$ & 35 & 19 & 16 & \\
\hline$>2$ & 42 & 9 & 33 & \\
\hline Clinical stage & & & & $<0.001$ \\
\hline $\mathrm{I} / \mathrm{II}$ & 39 & 22 & 17 & \\
\hline III/IV & 38 & 6 & 32 & \\
\hline Lymph node metastasis & & & & 0.006 \\
\hline$\leq 3$ & 39 & 20 & 19 & \\
\hline$>3$ & 38 & 8 & 30 & \\
\hline Distant metastasis & & & & 0.010 \\
\hline Presence & 45 & 11 & 34 & \\
\hline Absence & 32 & 17 & 15 & \\
\hline Estrogen receptor status & & & & 0.575 \\
\hline Positive & 38 & 15 & 23 & \\
\hline Absence & 39 & 13 & 26 & \\
\hline Progesterone receptor status & & & & 0.659 \\
\hline Presence & 47 & 18 & 29 & \\
\hline Absence & 30 & 10 & 20 & \\
\hline Epidermal growth factor receptor 2 status & & & & 0.862 \\
\hline Presence & 43 & 16 & 27 & \\
\hline Absence & 34 & 12 & 22 & \\
\hline
\end{tabular}

miR, microRNA.
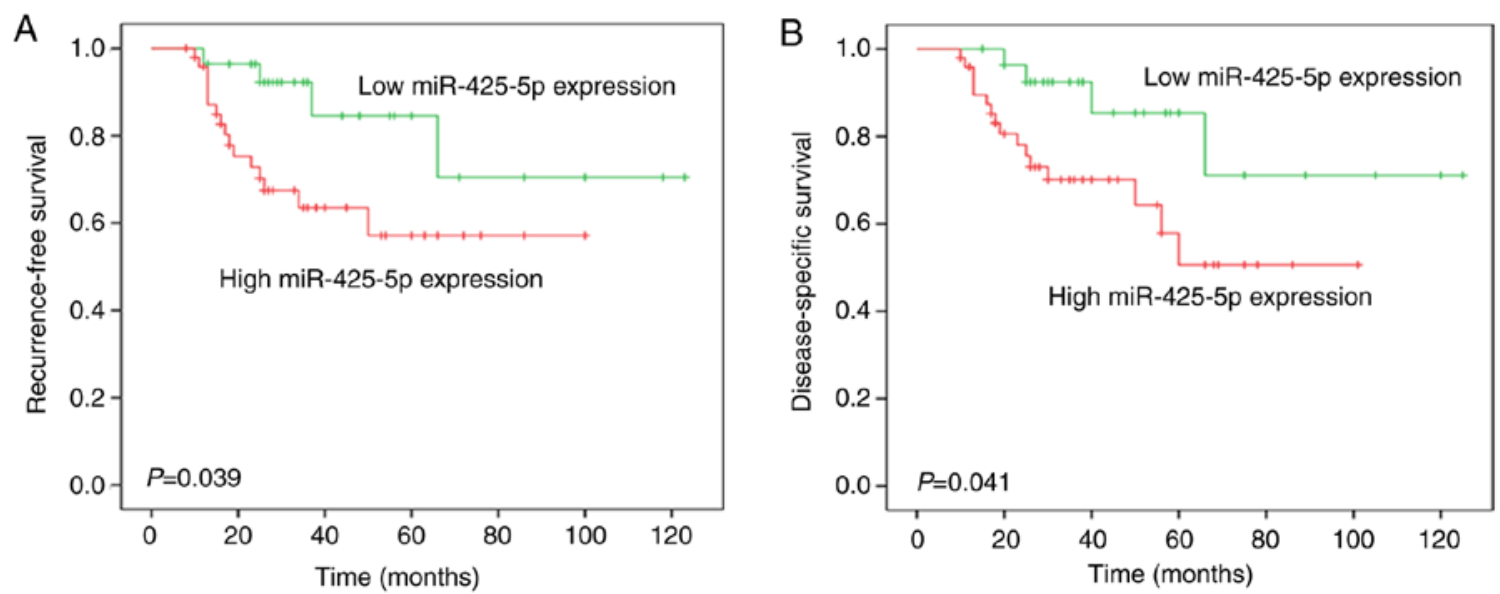

Figure 2. Kaplan-Meier survival curves of patients with BC according to miR-425-5p expression. (A) Kaplan-Meier analysis of recurrence-free survival in BC patients with high and low miR-425-5p expression. (B) Kaplan-Meier analysis of disease-specific survival in BC patients with high and low miR-425-5p expression. miR, microRNA; BC, breast cancer.

patients with $B C$. The association between miR-425-5p expression and the clinicopathological characteristics of patients with $\mathrm{BC}$ was analyzed. High miR-425-5p expression was significantly associated with tumor size, clinical 
Table II. Univariate and multivariate analysis of the prognostic variables influencing recurrence-free survival in patients with breast cancer.

\begin{tabular}{|c|c|c|c|c|c|}
\hline \multirow[b]{2}{*}{ Variables } & \multirow[b]{2}{*}{ Cases, $\mathrm{n}$} & \multicolumn{2}{|c|}{ Univariate analysis } & \multicolumn{2}{|c|}{ Multivariate analysis } \\
\hline & & $\mathrm{HR}(95 \% \mathrm{CI})$ & P-value & HR $(95 \%$ CI $)$ & P-value \\
\hline Age, years & & $0.348(0.210-1.364)$ & 0.470 & & \\
\hline$<45$ & 30 & & & & \\
\hline$\geq 45$ & 47 & & & & \\
\hline Tumor size, $\mathrm{cm}$ & & $1.044(0.531-2.017)$ & 0.014 & $1.184(0.821-2.647)$ & 0.017 \\
\hline$\leq 2$ & 35 & & & & \\
\hline$>2$ & 42 & & & & \\
\hline Clinical stage & & $1.504(1.047-3.647)$ & 0.029 & $1.418(0.889-2.691)$ & 0.033 \\
\hline $\mathrm{I} / \mathrm{II}$ & 39 & & & & \\
\hline III/IV & 38 & & & & \\
\hline Lymph node metastasis & & $1.773(0.941-2.097)$ & 0.026 & $1.524(0.862-3.394)$ & 0.020 \\
\hline$\leq 3$ & 39 & & & & \\
\hline$>3$ & 38 & & & & \\
\hline Distant metastasis & & $0.943(0.430-1.813)$ & 0.004 & $0.887(0.397-1.530)$ & 0.009 \\
\hline Presence & 45 & & & & \\
\hline Absence & 32 & & & & \\
\hline Estrogen receptor status & & $1.009(0.473-1.820)$ & 0.679 & & \\
\hline Presence & 38 & & & & \\
\hline Absence & 39 & & & & \\
\hline Progesterone receptor status & & $0.873(1.047-3.974)$ & 0.407 & & \\
\hline Presence & 47 & & & & \\
\hline Absence & 30 & & & & \\
\hline Epidermal growth factor receptor 2 status & & $1.340(1.873-3.911)$ & 0.637 & & \\
\hline Presence & 43 & & & & \\
\hline Absence & 34 & & & & \\
\hline microRNA-425-5p expression & & $1.833(0.947-3.075)$ & 0.007 & $1.771(0.994-2.647)$ & 0.013 \\
\hline High & 49 & & & & \\
\hline Low & 28 & & & & \\
\hline
\end{tabular}

HR, hazard ratio; CI, confidence interval.

stage, lymph node metastasis and distant metastasis $(\mathrm{P}<0.05$; Table I). Kaplan-Meier analysis revealed that patients with high miR-425-5p expression had significantly shorter RFS and DSS times compared with those with low miR-425-5p expression (Fig. 2). Univariate analysis for RFS in patients with BC is presented in Table II. Subsequent multivariate analysis demonstrated that tumor size ( $\mathrm{HR}, 1.184 ; \mathrm{P}=0.017)$, clinical stage $(\mathrm{HR}, 1.418 ; \mathrm{P}=0.033)$, lymph node metastasis (HR, 1.524; $\mathrm{P}=0.020)$, distant metastasis (HR, 0.887; $\mathrm{P}=0.009)$ and miR-425-5p level (HR, 1.771; $\mathrm{P}=0.013)$ were independent prognostic factors for RFS in patients with $\mathrm{BC}$ (Table II).

In addition, univariate analysis was performed for DSS in patients with BC, and results are presented in Table III. Subsequent multivariate analysis showed that tumor size (HR, 1.190; $\mathrm{P}=0.037)$, clinical stage $(\mathrm{HR}, 1.938 ; \mathrm{P}=0.030)$, lymph node metastasis (HR, 1.619; $\mathrm{P}=0.019)$, distant metastasis (HR, 1.473; $\mathrm{P}=0.019)$ and miR-425-5p level (HR, 1.074;
$\mathrm{P}=0.015)$ were independent prognostic factors for DSS in patients with BC (Table III).

miR-425-5p promotes cell proliferation and migration in $B C$. Among the BC cell lines, the expression of miR-425-5p was lowest in MCF-7 cells and highest in MDA-MB-231 cells (Fig. 1B). Therefore, these two cell lines were selected for subsequent experiments. To investigate the biological role of miR-425-5p on proliferation of BC cells, CCK-8 assays showed that knockdown of miR-425-5p expression significantly inhibited MDA-MB-231 and MCF-7 cell proliferation (Fig. 3A and B). Colony formation assays also revealed that reducing the expression of $\mathrm{miR}-425-5 \mathrm{p}$ resulted in reduced colony number in MDA-MB-231 and MCF-7 cells (Fig. 3C). Transwell assays indicated that knockdown of miR-425-5p inhibited migration in MDA-MB-231 and MCF-7 cells (Fig. 3D). However, knockdown of miR-425-5p had no significant effect on the invasive ability of MDA-MB-231 
Table III. Univariate and multivariate analysis of the prognostic variables influencing disease-specific survival in patients with breast cancer.

\begin{tabular}{|c|c|c|c|c|c|}
\hline \multirow[b]{2}{*}{ Variables } & \multirow[b]{2}{*}{ Cases, $\mathrm{n}$} & \multicolumn{2}{|c|}{ Univariate analysis } & \multicolumn{2}{|c|}{ Multivariate analysis } \\
\hline & & $\mathrm{HR}(95 \% \mathrm{CI})$ & P-value & $\mathrm{HR}(95 \% \mathrm{CI})$ & P-value \\
\hline Age, years & & $0.631(0.510-1.881)$ & 0.607 & & \\
\hline$<45$ & 30 & & & & \\
\hline$\geq 45$ & 47 & & & & \\
\hline Tumor size, $\mathrm{cm}$ & & $1.204(0.765-1.947)$ & 0.030 & $1.190(0.843-2.108)$ & 0.037 \\
\hline$\leq 2$ & 35 & & & & \\
\hline$>2$ & 42 & & & & \\
\hline Clinical stage & & $1.881(1.238-3.705)$ & 0.027 & $1.938(1.047-3.447)$ & 0.030 \\
\hline $\mathrm{I} / \mathrm{II}$ & 39 & & & & \\
\hline III/IV & 38 & & & & \\
\hline Lymph node metastasis & & $1.077(0.647-1.849)$ & 0.013 & $1.619(0.731-1.667)$ & 0.019 \\
\hline$\leq 3$ & 39 & & & & \\
\hline$>3$ & 38 & & & & \\
\hline Distant metastasis & & $1.647(0.840-2.661)$ & 0.020 & $1.473(0.845-2.304)$ & 0.019 \\
\hline Presence & 45 & & & & \\
\hline Absence & 32 & & & & \\
\hline Estrogen receptor status & & $0.660(0.843-2.614)$ & 0.431 & & \\
\hline Presence & 38 & & & & \\
\hline Absence & 39 & & & & \\
\hline Progesterone receptor status & & $1.243(0.842-1.994)$ & 0.377 & & \\
\hline Presence & 47 & & & & \\
\hline Absence & 30 & & & & \\
\hline Epidermal growth factor receptor 2 status & & $1.084(1.234-2.941)$ & 0.740 & & \\
\hline Presence & 43 & & & & \\
\hline Absence & 34 & & & & \\
\hline microRNA-425-5p expression & & $1.453(0.534-1.882)$ & 0.019 & $1.074(0.947-2.334)$ & 0.015 \\
\hline High & 49 & & & & \\
\hline Low & 28 & & & & \\
\hline
\end{tabular}

HR, hazard ratio; CI, confidence interval.

and MCF-7 cells (Fig. S1). Moreover, decreased miR-425-5p expression significantly inhibited EdU uptake, representing the proliferation of cells, in MDA-MB-231 and MCF-7 cells (Fig. 3E).

PTEN is a direct target of $m i R-425-5 p$. Using an online target prediction tool, it was found that PTEN may be a direct target of miR-425-5p (Figs. 4A and S2). To further verify that miR-425-5p biologically targets PTEN, a luciferase reporter assay was performed. The results indicated that co-transfection with a miR-425-5p inhibitor significantly promoted luciferase activity in cells transfected with WT PTEN 3'UTR. However, increase no luciferase activity was observed in cells co-transfected with MUT PTEN 3'UTR (Fig. 4B). Additionally, in cells with decreased expression of miR-425-5p, the expression of PTEN was significantly increased (Fig. 4C and D).

Furthermore, PTEN mRNA was lower in BC tissues compared with that in paired adjacent tissue (Fig. 5A). PTEN
mRNA expression levels inversely correlated with expression of miR-425-5p (Fig. 5B). Similarly, the expression of PTEN was found to be lower in BC cells compared with normal mammary epithelial cells (Fig. 5C).

Overexpression of PTEN partially rescues miR-425-5p-mediated effects on BC cells. To further confirm that PTEN is a functional target gene of miR-425-5p, the expression of PTEN was restored by transfecting MDA-MB-231 and MCF-7 cells with a PTEN-containing plasmid (pcDNA-PTEN). Overexpression of PTEN compared to controls (untransfected cells and empty vector) was confirm by RT-qPCR(Fig. S3). Co-transfection with pre-miR-425-5p and pcDNA-PTEN resulted in increased PTEN protein levels (Fig. 6A). Overexpression of miR-425-5p significantly promoted cell proliferation and migration in MDA-MB-231 and MCF-7 (Fig. 6B-E). Overexpression of PTEN significantly inhibited the promotional effects of miR-425-5p on proliferation and migration in MDA-MB-231 and MCF-7 
A

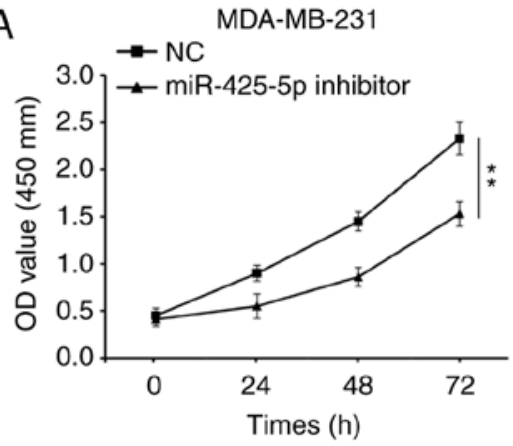

C
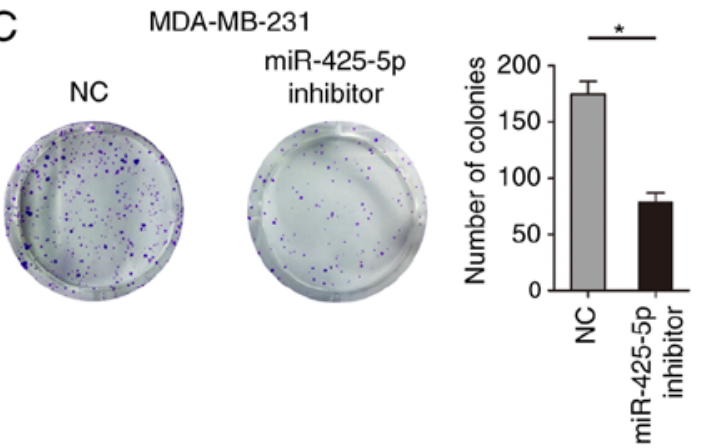

D
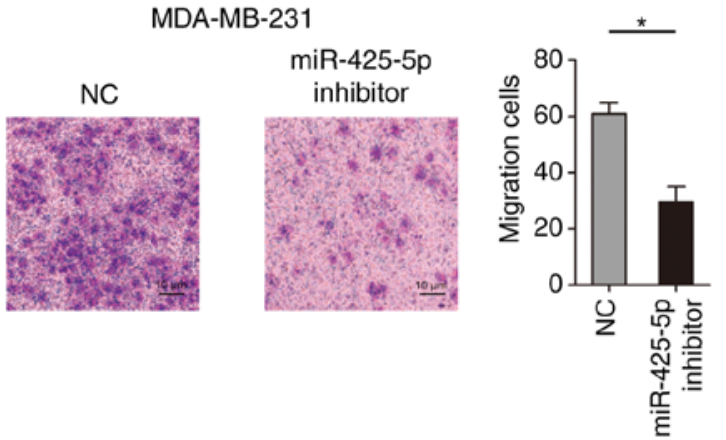

E

MDA-MB-231

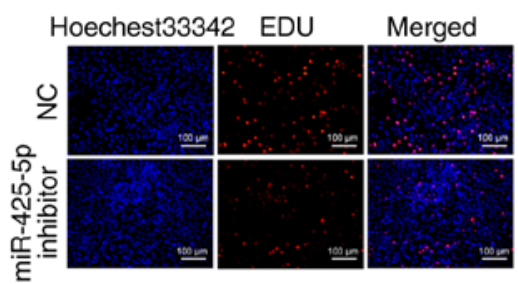

B

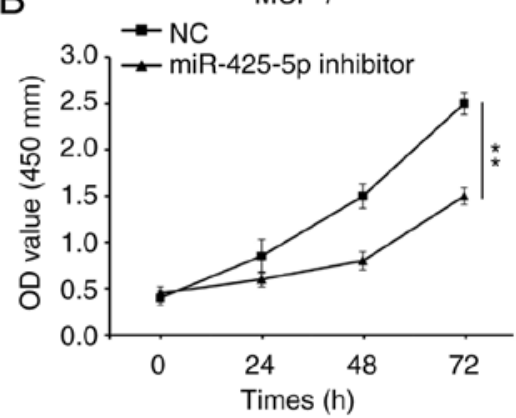

MCF-7

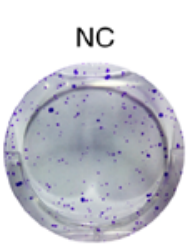

miR-425-5p inhibitor
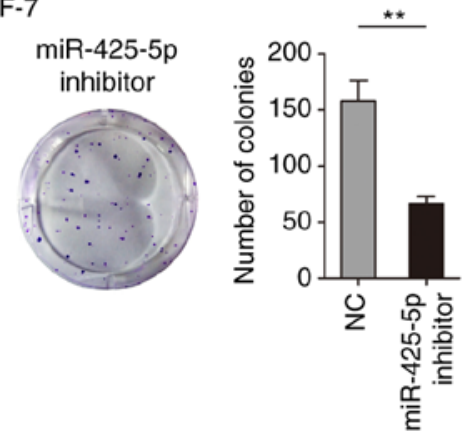

MCF-7

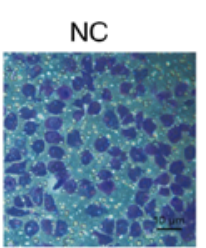

miR-425-5p inhibitor
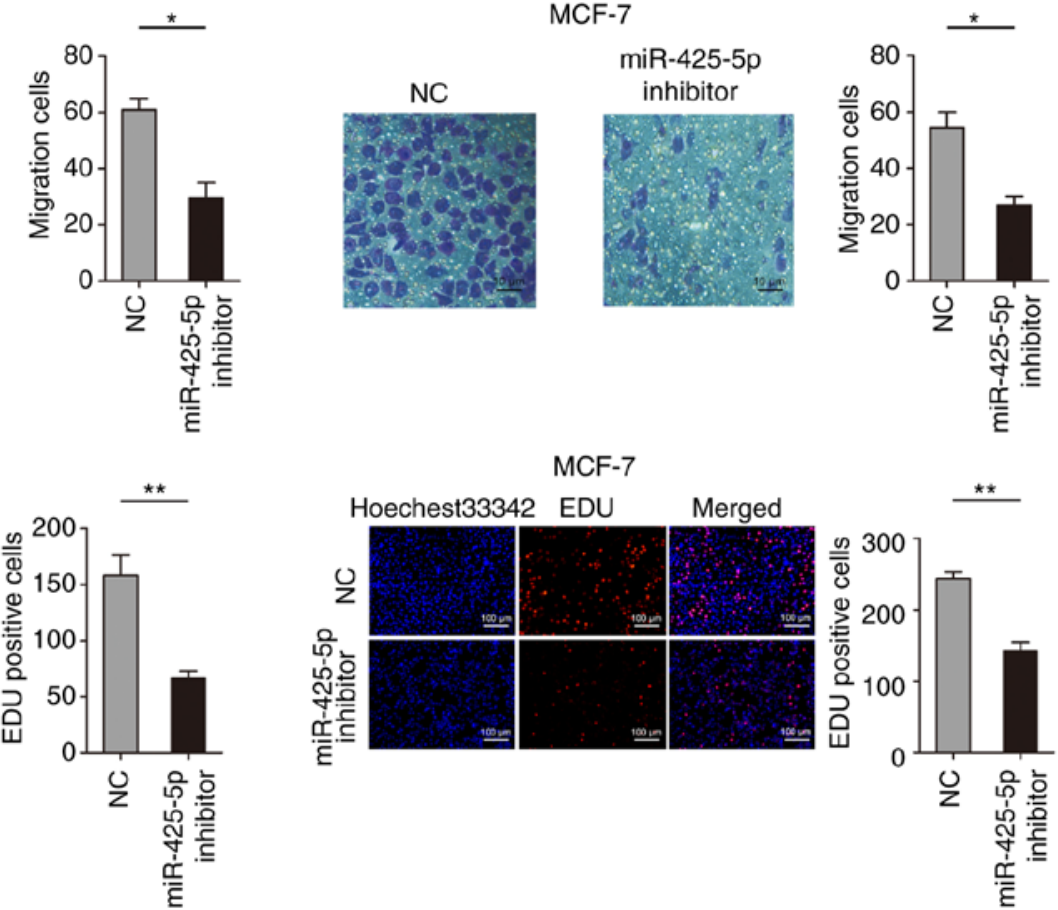

MCF-7
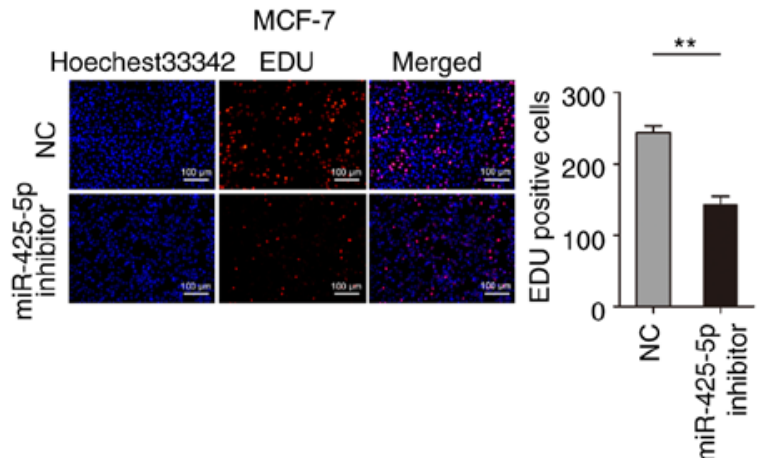

Figure 3. Knockdown of miR-425-5p inhibits BC cell proliferation and migration. (A-B) Proliferation; (C) colony formation assays; (D) Transwell migration assays; and (E) EdU uptake in MCF-7 and MDA-MB-231 cells transfected with miR-425-5p inhibitor. " $\mathrm{P}<0.05$ and ${ }^{* *} \mathrm{P}<0.01$. miR, microRNA; BC, breast cancer; NC, negative control.

cells (Fig. 6B-E). These results suggest that miR-425-5p plays a biological role through PTEN.

\section{Discussion}

$\mathrm{BC}$ is the most common type of tumor in women worldwide (1). A previous study found that there are $\sim 300,000$ new patients with $\mathrm{BC}$ in China each year (3). The incidence of BC in China is lower than that in western countries (3); however, due to the large population of China, the number and growth rate of the disease are among the highest in the world, and there are many young patients $(20,21)$. Therefore, effective molecular targets for the diagnosis and treatment of $\mathrm{BC}$ are urgently required. The results of the current study indicate that miR-425-5p is upregulated in $\mathrm{BC}$, and high expression of miR-425-5p is associated with poor prognosis of patients with $\mathrm{BC}$. Therefore, miR-425-5p may be a potential therapeutic target for BC.

As the roles of miRNAs have been investigated more thoroughly, miR-425-5p has been shown to play an important role in the progression of various types of cancer. FMR1 autosomal 

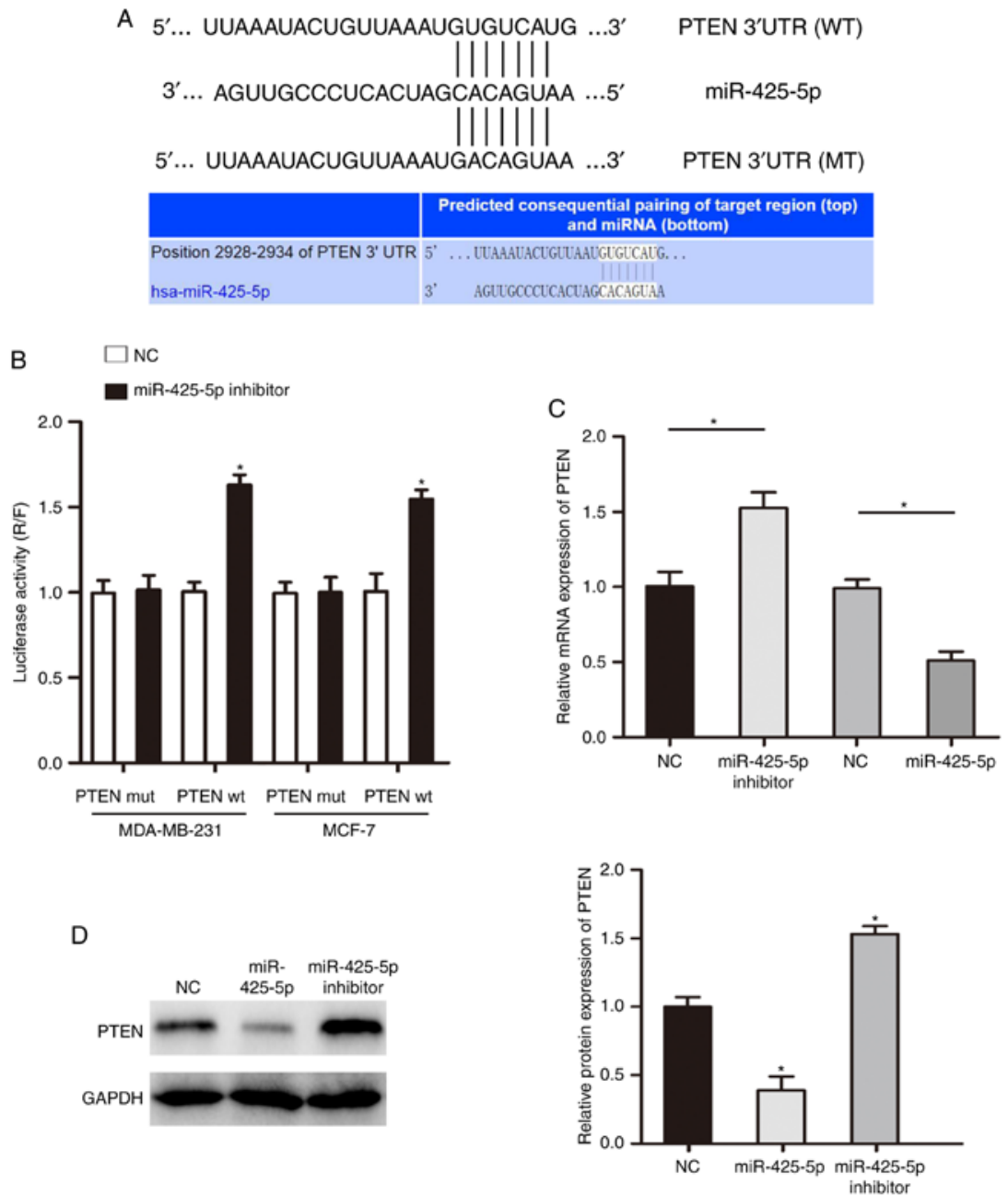

Figure 4. PTEN is a direct target of miR-425-5p. (A) Sequence of miR-425-5p putative binding site in the 3'UTR of PTEN. (B) Luciferase activity in MDA-MB-231 cells transfected with miR-425-5p inhibitor and WT or MUT 3'UTR of PTEN. (C) mRNA levels of PTEN in MDA-MB-231 cells transfected with pre-miR-425-5p or miR-425-5p inhibitor. (D) Western blot analysis of PTEN protein levels in MDA-MB-231 cells transfected with pre-miR-425-5p or miR-425-5p inhibitor. " $\mathrm{P}<0.05$. miR, microRNA; BC, breast cancer; NC, negative control; UTR, untranslated region; PTEN, phosphatase and tensin homolog.
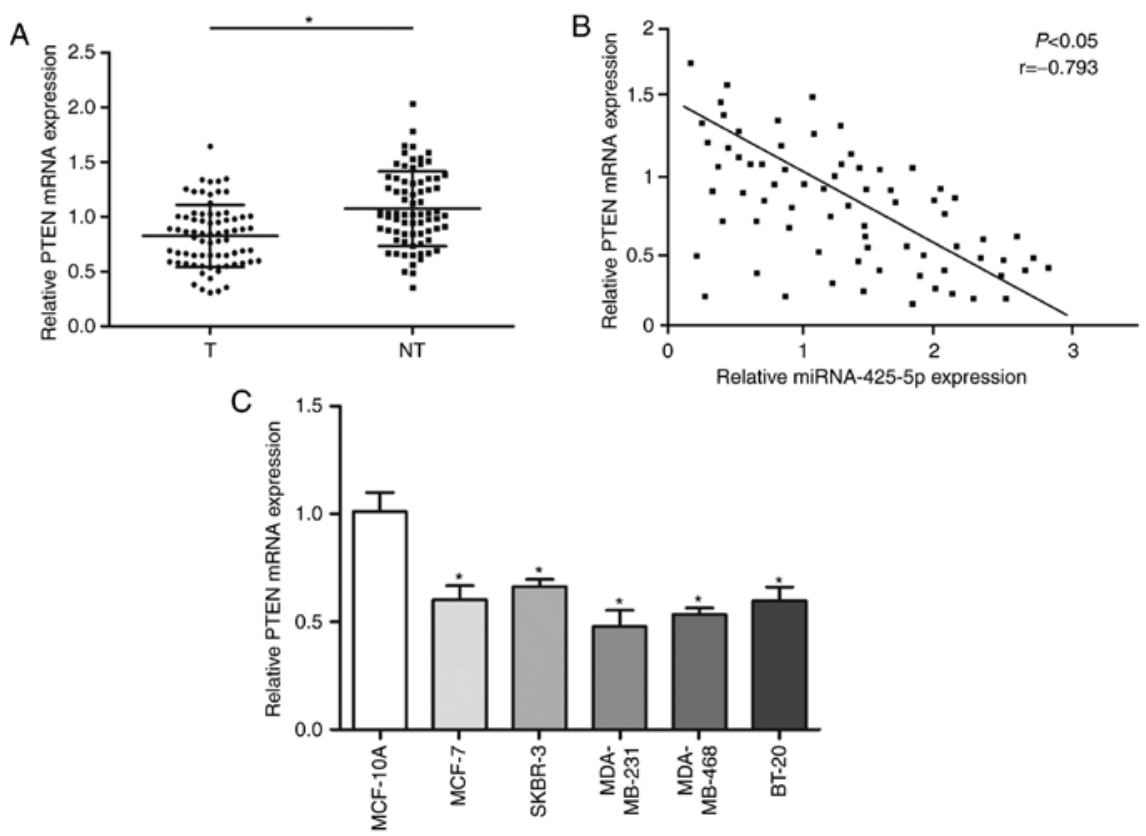

Figure 5. Expression of PTEN in BC tissues and cell lines. (A) Relative expression of PTEN in BC tumor tissue and paired adjacent tissue. (B) Correlation analysis of miR-425-5p and PTEN expression in BC tissues. (C) Relative expression of miR-425-5p in BC cell lines. "P<0.05. miR, microRNA; BC, breast cancer; NC, negative control; T, tumor tissue; NT, paired adjacent tissue. 

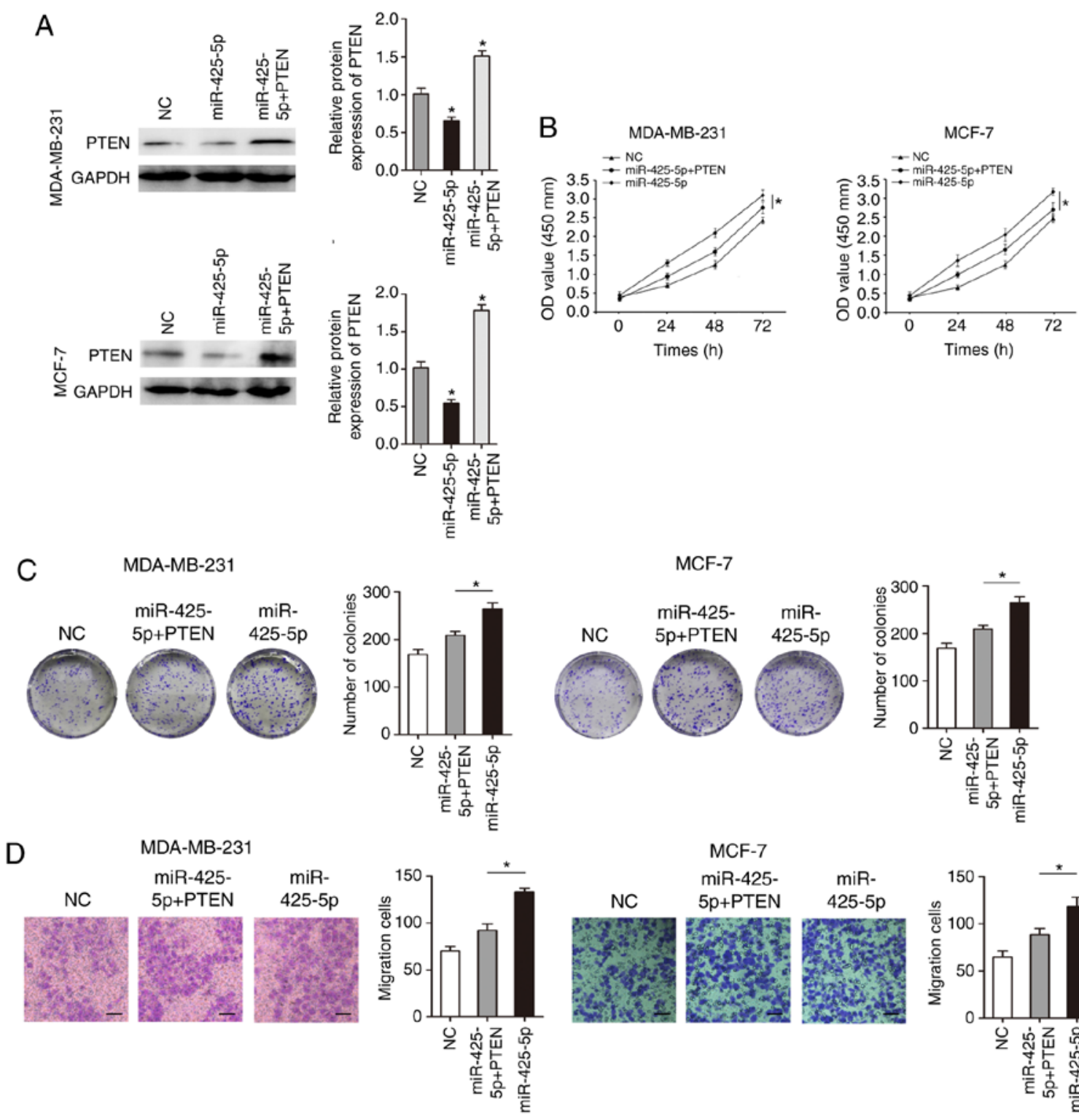

E

MDA-MB-231
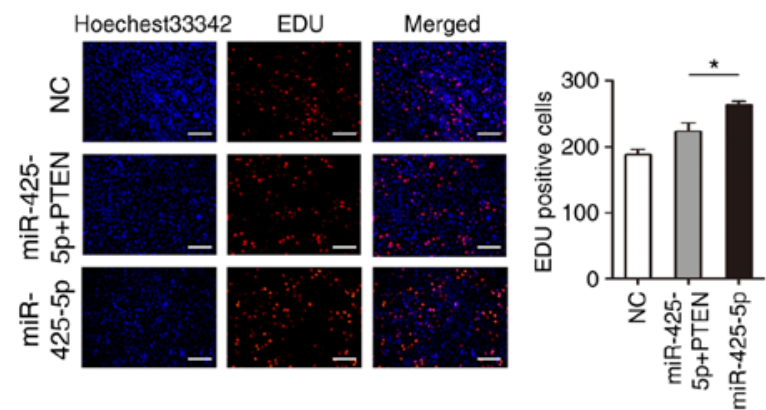

MCF-7
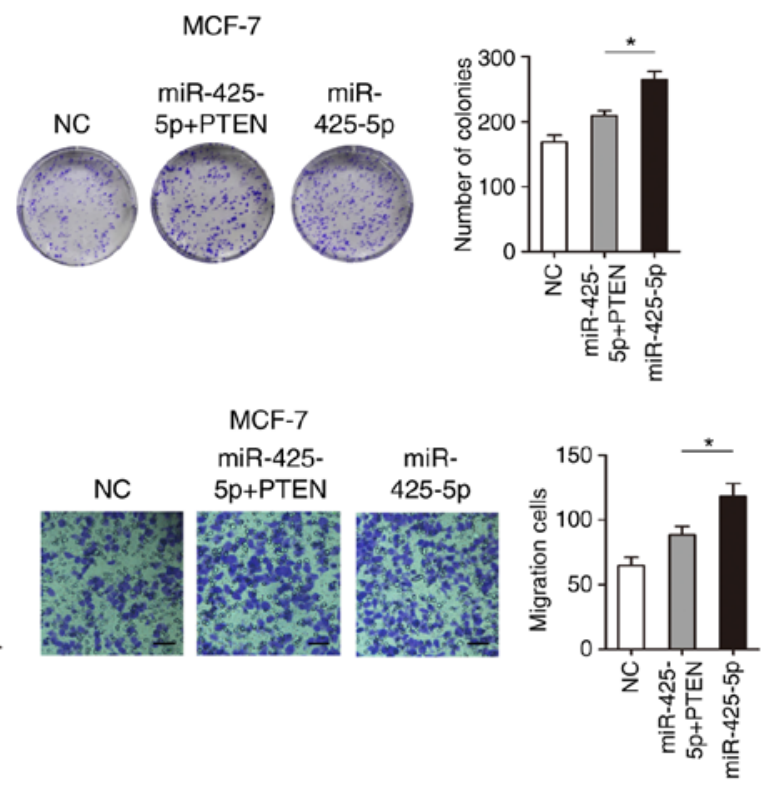

MCF-7

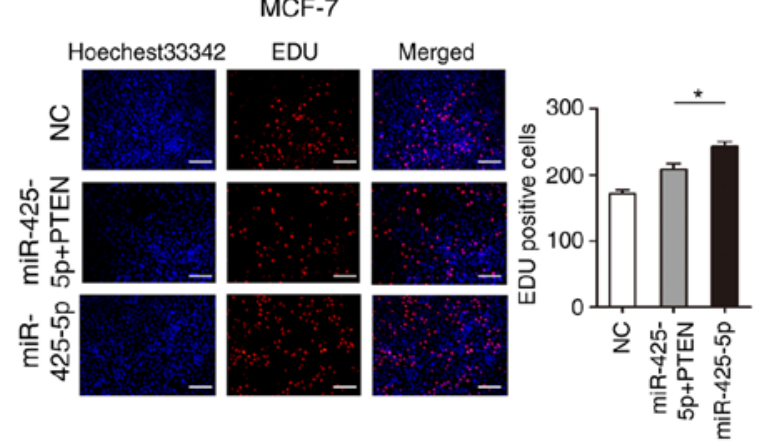

Figure 6. Overexpression of PTEN partially rescues miR-425-5p-mediated effects on BC cells. (A) Western blot analysis of PTEN protein level; (B) proliferation; (C) colony formation assays; (D) Transwell migration assays; and (E) EdU uptake in MCF-7 and MDA-MB-231 cells transfected with pcDNA-PTEN and pre-miR-425-5p. ${ }^{*} \mathrm{P}<0.05$. miR, microRNA; BC, breast cancer; NC, negative control.

homolog 1 regulates the expression of $\mathrm{miR}-425-5 \mathrm{p}$ and MIR17HG, thereby promoting the malignant development of glioma cells (22). miR-425-5p has also been found to increase the resistance of colorectal cancer to chemotherapeutic drugs by regulating the expression of PDCD10, suggesting that miR-425-5p may have potential as a new target to enhance the sensitivity of colorectal cancer to chemotherapeutic drugs (23). In osteosarcoma cells, increased expression of miR-425-5p can significantly increase the expression of MALAT1 and TUG1 and activate the $\mathrm{Wnt} / \beta$-catenin signaling pathway and promote the development of the malignant biological processes of the osteosarcoma process (24). The findings of the current study 
are consistent with these previous studies. Overexpression of miR-425-5p was found to promote proliferation and migration of BC cells, and decreased expression of miR-425-5p inhibited the proliferation and migration of BC cells. PTEN was identified as a target of miR-425-5p, and overexpression of PTEN partially inhibited the promotional effect of miR-425-5p in BC cells.

Previous studies suggest that four of the five miR-425-5p targets identified in the current study are not closely associated with biological functions of cancer cells or their specific functions are unknown $(25,26)$. However, PTEN is a protein phosphatase that may be involved in cellular regulation through dephosphorylation $(27,28)$. Phosphorylation and dephosphorylation are important ways to regulate cellular activity, and many oncogene products stimulate cell growth through phosphorylation (29-31). Through miRNA database prediction and experimental verification, PTEN predicted found to be a target of miR-425-5piIn the current study. In gastric cancer, PDZ domain-containing 1 inhibits the phosphorylation of PTEN at the S380/T382/T383 cluster by direct interaction with PTEN, further enhancing the ability of PTEN to inhibit the activation of PI3K/AKT (32). A previous study found that zinc finger HIT-type containing 1 affected the malignant development of BC by upregulating PTEN and inactivating the PI3K/AKT/mTOR pathway (33). In the present study, PTEN expression was revealed to be reduced in BC tissues, and miR-425-5p was shown to negative regulate PTEN expression. Additionally, restoration of PTEN expression in BC cells with miR-425-5p overexpression partially reversed the effects of the miRNA on proliferation and migration.

In conclusion, the findings of the present study demonstrate that miR-425-5p regulates $\mathrm{BC}$ cell proliferation by influencing PTEN expression. This provides new information regarding the occurrence and development of $\mathrm{BC}$, and provides a potential novel target for molecular therapy for patients with $\mathrm{BC}$.

\section{Acknowledgements}

Not applicable.

\section{Funding}

This study was supported by the Key Research Projects on Application Foundation of Sichuan Science and Technology Department (grant no. 2017JY0030).

\section{Availability of data and materials}

All data generated or analyzed during this study are included in this published article.

\section{Author's contributions}

SX and MX designed and conducted the experiments and wrote the manuscript. HZ, JL and ZW provided the research materials and analyzed the data. All authors read and approved the manuscript and agree to be accountable for all aspects of the research.

\section{Ethics approval and consent to participate}

All protocols involving the use of humans were approved by the Ethics Review Committee of the Yibin First People's Hospital (Yibin, China) and the Ethics Review Committee of Southwest Medical University (Luzhou, China). Written informed consent was obtained from all patients for the use of their tissue in this study.

\section{Patient consent for publication}

Not applicable.

\section{Competing interests}

The authors declare that they have no competing interests.

\section{References}

1. Davidson NE, Armstrong SA, Coussens LM, Cruz-Correa MR, DeBerardinis RJ, Doroshow JH, Foti M, Hwu P, Kensler TW Morrow M, et al: AACR cancer progress report 2016. Clin Cancer Res 22 (Suppl 19): S1-S137, 2016.

2. McGuire A, Brown JA, Malone C, McLaughlin R and Kerin MJ: Effects of age on the detection and management of breast cancer. Cancers (Basel) 7: 908-929, 2015.

3. Chen W, Zheng R, Baade PD, Zhang S, Zeng H, Bray F, Jemal A, $\mathrm{Yu}$ XQ and He J: Cancer statistics in China, 2015. CA Cancer J Clin 66: 115-132, 2016.

4. Christenson JL, Butterfield KT, Spoelstra NS, Norris JD, Josan JS, Pollock JA, McDonnell DP, Katzenellenbogen BS, Katzenellenbogen JA and Richer JK: MMTV-PyMT and derived Met-1 mouse mammary tumor cells as models for studying the role of the androgen receptor in triple-negative breast cancer progression. Horm Cancer 8: 69-77, 2017.

5. Gu G, Dustin D and Fuqua SA: Targeted therapy for breast cancer and molecular mechanisms of resistance to treatment. Curr Opin Pharmacol 31: 97-103, 2016.

6. Riobo-Del Galdo NA, Lara Montero Á and Wertheimer EV: Role of hedgehog signaling in breast cancer: Pathogenesis and therapeutic. Cells 8: E375, 2019.

7. Harbeck N and Gnant M: Breast cancer. Lancet 389: 1134-1150, 2017.

8. Wu H, Zhang W, Wu Z, Liu Y, Shi Y, Gong J, Shen W and Liu C: miR-29c-3p regulates DNMT3B and LATS1 methylation to inhibit tumor progression in hepatocellular carcinoma. Cell Death Dis 10: 48, 2019.

9. Du H, Xu Q, Xiao S, Wu Z, Gong J, Liu C, Ren G and Wu H: MicroRNA-424-5p acts as a potential biomarker and inhibits proliferation and invasion in hepatocellular carcinoma by targeting TRIM29. Life Sci 224: 1-11, 2019.

10. Hausser $\mathbf{J}$ and Zavolan $\mathbf{M}$ : Identification and consequences of miRNA-target interactions-beyond repression of gene expression. Nat Rev Genet 15: 599-612, 2014.

11. Cohen A, Burgos-Aceves MA and Smith Y: Estrogen repression of microRNA as a potential cause of cancer. Biomed Pharmacother 78: 234-238, 2016.

12. Bartel DP: Metazoan microRNAs. Cell 173: 20-51, 2018.

13. Hobert O: Gene regulation by transcription factors and microRNAs. Science 319: 1785-1786, 2008.

14. Bartel DP: MicroRNAs: Genomics, biogenesis, mechanism, and function. Cell 116: 281-297, 2004.

15. Quan J, Li Y, Pan X, Lai Y, He T, Lin C, Zhou L, Zhao L, Sun S, Ding Y, et al: Oncogenic miR-425-5p is associated with cellular migration, proliferation and apoptosis in renal cell carcinoma. Oncol Lett 16: 2175-2184, 2018.

16. Zhang JY, Su XP, Li YN and Guo YH: MicroRNA-425-5p promotes the development of prostate cancer via targeting forkhead box J3. Eur Rev Med Pharmacol Sci 23: 547-554, 2019.

17. Jiang C, Cao S, Li N, Jiang L and Sun T: PD-1 and PD-L1 correlated gene expression profiles and their association with clinical outcomes of breast cancer. Cancer Cell Int 19: 233, 2019. 
18. Jiang Y,Liu Y, Tan X, Yu S and Luo J: TPX2 as a novel prognostic indicator and promising therapeutic target in triple-negative breast cancer. Clin Breast Cancer S1526-S8209: Jun 13, 2019 (Epub ahead of print).

19. Livak KJ and Schmittgen TD: Analysis of relative gene expression data using real-time quantitative PCR and the 2(-Delta Delta $\mathrm{C}(\mathrm{T}))$ method. Methods 25: 402-408, 2001.

20. Turashvili $\mathrm{G}$ and Brogi E: Tumor heterogeneity in breast cancer. Front Med 4: 227, 2017.

21. Hu L, Gao Y, Cao Y, Zhang Y, Xu M, Wang Y, Jing Y, Guo S, Jing $\mathrm{F}, \mathrm{Hu} \mathrm{X}$ and $\mathrm{Zhu} \mathrm{Z}$ : Identification of arginine and its 'downstream' molecules as potential markers of breast cancer. IUBMB Life 68: 817-822, 2016.

22. Cao S, Zheng J, Liu X, Liu Y, Ruan X, Ma J, Liu L, Wang D, Yang $\mathrm{C}$, Cai $\mathrm{H}$, et al: FXR1 promotes the malignant biological behavior of glioma cells via stabilizing MIR17HG. J Exp Clin Cancer Res 38: 37,2019.

23. Zhang Y, Hu X, Miao X, Zhu K, Cui S, Meng Q, Sun J and Wang T: MicroRNA-425-5p regulates chemoresistance in colorectal cancer cells via regulation of programmed cell death 10 . J Cell Mol Med 20: 360-369, 2016.

24. Yang G, Zhang C, Wang N and Chen J: miR-425-5p decreases LncRNA MALAT1 and TUG1 expressions and suppresses tumorigenesis in osteosarcoma via Wnt/ $\beta$-catenin signaling pathway. Int J Biochem Cell Biol 111: 42-51, 2019.

25. Charzewska A, Rzońca S, Janeczko M, Nawara M, Smyk M, Bal J and Hoffman-Zacharska D: A duplication of the whole KIAA2022 gene validates the gene role in the pathogenesis of intellectual disability and autism. Clin Genet 88: 297-299, 2015 .
26. Melchior B, Mittapalli GK, Lai C, Duong-Polk K, Stewart J, Güner B, Hofilena B, Tjitro A, Anderson SD, Herman DS, et al: Tau pathology reduction with SM07883, a novel, potent, and selective oral DYRK1A inhibitor: A potential therapeutic for Alzheimer's disease. Aging Cell 18: e13000, 2019.

27. Wu J, Chen H, Ye M, Wang B, Zhang Y, Sheng J, Meng T and Chen H: Downregulation of long noncoding RNA HCP5 contributes to cisplatin resistance in human triple-negative breast cancer via regulation of PTEN expression. Biomed Pharmacother 115: $108869,2019$.

28. Zhu L, Wang X, Wang T, Zhu W and Zhou X: miR-494-3p promotes the progression of endometrial cancer by regulating the PTEN/PI3K/AKT pathway. Mol Med Rep 19: 581-588, 2019.

29. Shen F, Zheng H, Zhou L, Li W, Liu J and Xu X: Identification of CD28 and PTEN as novel prognostic markers for cervical cancer. J Cell Physiol 234: 7004-7011, 2019.

30. Liang L, Williams MD and Bell D: Expression of PTEN, androgen receptor, HER $2 /$ neu, cytokeratin $5 / 6$, estrogen receptor-beta, HMGA2, and PLAG1 in salivary duct carcinoma. Head Neck Pathol Nov 2, 2018 (Epub ahead of print).

31. Zhu L, Zhang C and Liu Q: PTEN S-nitrosylation by NOS1 inhibits autophagy in NPC cells. Cell Death Dis 10: 306, 2019.

32. Zhao C, Tao T, Yang L, Qin Q, Wang Y, Liu H, Song R, Yang X, Wang Q, Gu S, et al: Loss of PDZK1 expression activates PI3K/AKT signaling via PTEN phosphorylation in gastric cancer. Cancer Lett 453: 107-121, 2019.

33. Cui C, Li S and Wu D: Znhit1 inhibits breast cancer by up-regulating PTEN to deactivate the PI3K/Akt/mTOR pathway. Life Sci 224: 204-211, 2019.

(i) (5) This work is licensed under a Creative Commons Attribution-NonCommercial-NoDerivatives 4.0 International (CC BY-NC-ND 4.0) License. 